Luis Armando González1

Luis Emesto Romano Martínez2

\title{
Reforma agraria y cooperativismo en El Salvador: antecedentes y perspectivas (1970-1996)
}

\section{Introducción}

Pese a los cambios que se han operado en la economía salvadoreña, el agro continúa siendo un problema aún irresuelto. En el pasado reciente se convirtió en el foco de conflictividad social que alimentó las protestas populares más importantes que ha conocido la historia contemporánea de El Salvador. Un antecedente de la efervescencia que vivió el campo salvadoreño en la década de los años setenta fue el levantamiento campesino de 1932, el cual anunció -como vislumbraron bien quienes se opusieron a la sindicalización campesina a partir de entonces - futuros conflictos cuya agudeza iba a estar correlacionada con el grado de desatención que empresarios, políticos y militares prestaran al problema agrario.

Así pues, la tierra ha sido el epicentro de las crisis más agudas que ha vivido El Salvador en el siglo XX. La guerra civil estuvo alimentada en sus orígenes por la extrema marginalidad a que se vio arrastrada la población campesina. En la postguerra, el agro todavía no ha recibido la atención que se merece, pues los empresarios y el gobiemo están anonadados por el auge del sector terciario, así como por una inserción de tipo maquilera en el proceso de globalización.

Ciertamente, el agro salvadoreño ha sido fuente de controversia desde la época de la conquista, aunque con mucha mayor intensidad a partir de la segunda mitad del siglo pasado con la expropiación de las tierras comunales y ejidales. El nivel de confrontación alcanzado por las desigualdades sociales que emanaron de la citada expropiación motivaron a los gobernantes de tumo, en 1980, a emprender un proceso de Reforma Agraria que perseguía fundamentalmente disminuir la concentración de la propiedad de la tierra y mejorar las condiciones de vida de los beneficiarios. Más de una década después de la reforma agraria no 
puede negarse que ésta alteró la propiedad de la tierra. Sin embargo, no alteró las condiciones de pobreza rural que la originaron.

En el presente artículo se busca presentar una evaluación de la reforma agraria que considere no sólo los resultados concretos arrojados por ésta, sino también el contexto económico y político en el cual ha tenido que desenvolverse y sus implicaciones sobre el movimiento cooperativo agropecuario. Para lo anterior, en el primer apartado se presentan las características más significativas del agro salvadoreño destacando sus marcadas tendencias hacia la concentración de la propiedad y la generación de pobreza rural. En el segundo apartado se exponen algunos antecedentes de transformación agraria y organización campesina que se remontan a la década de 1970 . En la tercera parte se ofrece una breve evaluación económica del sector cooperativo de la reforma agraria de la década de los años ochenta y se presentan algunos elementos que podrían explicarla. Finalmente, se destacan las principales conclusiones acerca del resultado de la reforma agraria, su contexto político y las perspectivas del cooperativismo en El Salvador.

\section{El agro salvadoreño (1970-1979)}

Como ha señalado Segundo Montes, la tierra ha sido el "epicentro de la crisis" en El Salvador no sólo en procesos históricos pasados (como el levantamiento de Anastasio Aquino en la primera mitad del siglo XIX o la insurrección de 1932), sino - y muy particularmente- en el proceso histórico de los años setenta. . Y ello por diversas razones, entre las que sobresalen la depauperización, descampesinización y proletarización de la población rural causada por la profundización del capitalismo en el agro salvadoreño ${ }^{4}$.

\subsection{Concentración de la tierra y profundización del capitalismo}

El Salvador poseía, durante el período que estamos considerando, una extensión de 21 mil kilómetros cuadrados. Pues bien, el 1.5 por ciento de la fincas concentraba un promedio de 302.35 hectáreas de extensión. Por su parte, esas fincas -que pertenecían a propietarios o arrendatarios- equivalían al 49.3 por ciento de todas las tierras cultivables. Un dato complementario es que el 48.9 por ciento de las fincas poseía el 4.8 por ciento de la superficie cultivable, con extensiones de 5 hectáreas promedio ${ }^{5}$. En opinión de Carlos R. Cabarrús, estos datos nos llevan a la inevitable conclusión de que un 1.5 por ciento de los propietarios agrícolas controlaban la mitad de las tierras cultivables en El Salvador ${ }^{6}$. En gran parte, estas tierras cultivables estaban destinadas a cultivos de exportación (café, algodón y caña de azúcar), mismos que, además de generarse a través de mecanismos de producción capitalista, articulaban la economía nacional al comercio intemacional del cual se dependía económicamente. Asimismo, estos sectores productivos se articulaban con otro sectores de la economía campesina, que se deterioraban progresivamente a medida que se profundizaban las relacio- 
nes de producción capitalista en el agro. Como resultado del avance en la producción capitalista del café, el algodón y la caña de azúcar, las parcelas campesinas fueron disminuyendo o desapareciendo, lo cual trajo un doble beneficio para los propietarios agrícolas: aumentaron sus ganancias con cultivos más rentables y obtuvieron mayor cantidad de mano de obra barata y radicada en los alrededores de las fincas? ${ }^{7}$.

Sin este dato estructural, como lo es la depredación capitalista de la economía campesina, no se puede comprender a cabalidad la rebeldía campesina en El Salvador ni las causas socioeconómicas que posibilitaron su organización. Como señala C. R. Cabarrús:

Para la lógica campesina, tener parcelas, aunque sean muy pequeñas, es imprescindible. Mientras se es propietario se puede gozar de cierta libertad ante un sistema que es siempre más poderoso. La lucha por la tierra se convierte pronto en una motivación de la organización. En esta carencia de tierra los campesinos irán encontrando la continua razón de su rebeldía. En un país como El Salvador, donde la tierra es poca, donde la población es tan numerosa, la tendencia ambiciosa del capital a despojar al campesino aumentará. Y esa tendencia fomentará irremediablemente la crisis ${ }^{\sharp}$.

Por otra parte, el examen del Producto Territorial Bruto (PTB) y la tasa de crecimiento acumulativo del sector agropecuario durante 1973-1978 revela que el crecimiento total del PTB fue del 18 por ciento, que para la agricultura alcanzó un 20 por ciento. Ahora bien, al analizar cada uno de los rubros, los que poseen una tasa más elevada son los productos de exportación: café, algodón y caña de azúcar (o los que están relacionados con ellos y son producidos en forma capitalista, como la semilla de algodón, tabaco, henequén). Mientras que los productos de consumo interno (arroz, maicillo, ganadería, silvicultura, pesca, apicultura y avicultura) tienen tasas de crecimiento que, unidas al proceso inflacionario de finales de los setenta, apenas alcanzaron a cubrir el crecimiento vegetativo de la población ${ }^{y}$.

La conclusión de Montes en torno a la política que se ha seguido en el sector agropecuario es la siguiente: "los productos de exportación y en general todos los que se cultivan predominantemente por un modo de producción capitalista son los que obtienen tasas de crecimiento más elevadas, y notablemente superiores a las de los demás productos, incluidos los de alimentación básica. En valores absolutos también se percibe la relevancia que tiene el café sobre cualquier otro producto, e incluso el algodón si se le incluye el subproducto de la semilla del algodón"10.

En este contexto, la economía salvadoreña dependía, en lo que se refiere al sector extemo, de la producción agrícola. Así, para 1960, el sector agrícola absorbía el 94 por ciento del total de exportaciones; en 1964, el 85 por ciento; 
en 1970, el 71 por ciento; en 1975, el 71 por ciento; y en 1978, el 72 por ciento". Estos datos muestran un crecimiento de las exportaciones durante el período, así como una diversificación de las mismas, lo cual permitió que del 94 por ciento del total en 1960 se elevara al 72 por ciento en 1978, porcentaje que es sumamente alto y refleja el predominio del sector agropecuario en el comercio externo de El Salvador. Asimismo, como hace notar Montes, los productos que predominaban en las exportaciones del país (café, algodón y caña de azúcar) se obtenían de las explotaciones capitalistas ${ }^{12}$.

La productividad, o rendimientos por unidad de terreno, del café era muy elevada desde mucho antes del período analizado. Sin embargo, durante la década este rubro tuvo un crecimiento muy escaso en comparación con otros rubros, como la caña de azúcar, el maíz o el frijol. En efecto, en 1976 el café alcanzó un rendimiento (QQ/Mz) de 10.73; el algodón, 12.38; la caña de azúcar, 53.44; el maíz, 22.9; el frijol, 11.52; y el arroz, 25.57. En 1977, los índices para los mismos rubros fueron los siguientes: el café alcanzó 11.24; el algodón, 10.70; la caña de azúcar, 60.22; el maíz, 23.25; el frijol, 9.78; el arroz, 26.01. Y en 1978: el café alcanzó 11.99; el algodón, 11.52; la caña de azúcar, 68.01; el maíz, 31.49; el frijol, 12.70; y el arroz, $36.17^{13}$.

Como puede observarse, la caña de azúcar fue el rubro que creció más, lo cual se explica en buena medida por la introducción de nueva tecnología en la producción cañera y por los incrementos de capital en ese rubro. Esto último se hace evidente si se analiza el financiamiento otorgado (en miles de colones) por los bancos comerciales e hipotecarios del país al sector agropecuario. El sector agropecuario recibió en 1975, 1976, 1977 y 1978 un total de 351 533, 500 326, 655568 y 585933 , respectivamente. Para esos mismos años, la agricultura se llevó 332 603, 476 890, 634646 y 558 766. De esos totales, el café percibió, en 1975, 150 023; en 1976, 249 650; en 1977, 346 431; y en 1978, 273 191. El algodón se llevó en 1975, 114 075; en 1976, 141 869; en 1977, 198 240; y en 1978, 200 537. La caña de azúcar recibió, en 1975, 20 082; en 1976, 42 036; en 1977,42504 ; y en $1978,38367^{14}$.

La concentración del financiamiento en el café, el algodón y la caña de azúcar se hace más notoria si se compara con el financiamiento recibido por el maíz, el frijol y el arroz, durante el mismo período. El maíz absorbió, en 1975, 15 117; en 1976, 13 842; en 1977, 9572 ; y en 1978, 11 317. El frijol recibió en 1975, 1 557; en 1976, 905; en 1977, 720; y en 1978, 1 542. Finalmente, el arroz percibió en 1975, 12 270; en 1976, 12 145; en 1977, 6 921; en 1978, $7587^{15}$.

Los datos anteriores comprueban, en opinión de Segundo Montes, que el sistema bancario nacional está en función de la reproducción del sistema capitalista salvadoreño, mismo que se sostiene a través de la producción agrícola y de la exportación del café, el algodón y lạ caña de azúcar. Como concluye este autor: 
El sistema bancario nacional está financiando, sosteniendo y privilegiando el modo de producción capitalista, lo que no es extraño si se tiene en cuenta la gran concentración oligárquica en todos los sectores de la economía salvadoreña... y si se tiene en cuenta que todo el sistema económico, político y social salvadoreño es capitalista. Efectivamente, del financiamiento concedido a la agricultura, casi el 50 por ciento se destina todos los años (...) al café, cerca del $\mathbf{4 0}$ por ciento al algodón, y en torno a un $\mathbf{6}$ por ciento a la caña de azúcar. Por otro lado, resulta casi risible la cantidad que se destina a la producción de granos básicos y al resto de productos del sector. Todo el sistema económico y financiero... está en función del modo de producción capitalista, y el aparato estatal igualmente, ya que el sistema bancario lo que hace es instrumentalizar las líneas de crédito concedidas por el gobierno y por el banco central de reservath.

\subsection{Depauperación rural}

Durante la década de los setenta, la población campesina vio deterioradas sus condiciones de vida, entre otras razones por el decremento en la producción de alimentos de su dieta básica (maíz, frijol, arroz, maicillo) o por el incremento en la producción de los mismos que no se compensa con el ritmo de crecimiento poblacional. En efecto, entre 1973 y 1977, la producción de granos básicos se mantuvo estable o disminuyó ${ }^{17}$, lo cual repercutió directamente en el deterioro de las condiciones de vida de la población rural que dispuso de una cantidad menor de alimentos y/o se vio imposibilitada de efectuar la operación de compra y venta de otros productos necesarios, por lo que tuvo que restringir sus gastos o buscar otras fuentes de ingresos para incrementar sus ingresos ${ }^{18}$.

Datos recabados por CIID-OEA señalan que, durante el período 1969-1978, la tasa de crecimiento anual para la producción agropecuaria fue de 3.5 por ciento, mientras que la tasa acumulativa en la demanda de productos agrícolas fue de 5.8 por ciento ${ }^{19}$. Por su parte, datos del Banco Central de Reserva (BCR) ${ }^{21}$ señalan que, entre 1975 y 1977, la tasa de crecimiento del producto agrícola fue de -3.9 por ciento, con lo cual el mismo se rezagó notablemente del ritmo de crecimiento de la población, contribuyendo a deteriorar las condiciones de vida de los sectores populares campesinos. Como señala Segundo Montes, a propósito de la producción de alimentos básicos durante 1950-1975:

Los productos de alimentación básica tienen tasas de crecimiento muy inferiores a las del crecimiento de la población, y en algunos casos, como el frijol, incluso negativo, con lo que la disponibilidad de alimentos para la población es menor año con año, y lógicamente serán la capas inferiores -que por otro lado son las mayoritarias - las que padecerán las consecuencias, y más si se considera... que va desapareciendo el modo de producción no capitalista, y el minifundio va reduciéndose en número y extensión, de modo que no podrán 
producir ni siquiera los alimentos que necesitarán durante el año, y tendrán que acudir al mercado de trabajo y de consumo ${ }^{21}$.

Pero las condiciones de vida de los sectores campesinos no se deterioran sólo por la escasez de los productos que constituyen la dieta alimenticia básica de la población rural. Hay otros factores que contribuyen sustancialmente a agudizar ese deterioro; entre estos factores uno de los más relevantes es la distribución del ingreso. Este indicador revela la disparidad existente entre el sector agrícola y el sector no agrícola de la economía nacional en cuanto a la captación de ingresos. Los datos básicos en este punto son los siguientes: las actividades agrícolas percibieron, en 1975, un total de ingresos de 28415 120; en 1977, 75238 851; en 1978, 65160 223; y en 1979, 60904 936. Asimismo, la Población Económicamente Activa (PEA) ocupada en estas actividades en esos años fue la siguiente: 394 530; 461 007; 414891 y 423 429. Finalmente, el ingreso per cápita en este sector y durante los años considerados se distribuyó del siguiente modo: $72.02,166.82,157.05$ y 143.83. En las actividades no agrícolas, el total de ingresos recibidos durante los años 1975-1979 fue el siguiente: en 1975, 12339 250; en 1977, 21557 061; en 1978, 37420 986; y en 1979, 41066 575. La PEA ocupada fue, para esos mismos años, la siguiente: 120 562; 146 476; 209 530; 216927. Finalmente, el ingreso per cápita se distribuyó del siguiente modo: 102.35, 147.17, 178.59 y $189.31^{22}$.

Los bajos niveles de ingresos en el sector agrícola se traducen en un deterioro del poder adquisitivo por parte de los habitantes del área rural. Y, como señala Montes, "como consecuencia del deterioro del poder adquisitivo en el campo (cuya población es mayoritaria en el país, 60 por ciento), la demanda interna del sector tiene que ser baja, e incluso negativa si se considera en términos de 'por habitante'. Esto confirma el proceso de depauperación del pueblo salvadoreño, y especialmente del habitante del campo"23.

En genera ${ }^{24}$, pues, durante la década de los setenta se produce un deterioro en las condiciones de vida de los sectores campesinos de los estratos más bajos. Por ello es que podemos concluir, con Segundo Montes, que el

fenómeno de depauperación en los estratos o en las capas inferiores de la población rural ha sido real en los últimos años, y que se ha agudizado al final de los mismos. Por otro lado, conviene no olvidar que estas capas constituyen la inmensa mayoría de la población, por lo que se ve que la profundización del modo de producción capitalista en el agro salvadoreño ha traído consigo, como primera consecuencia, un deterioro de las condiciones de vida del campesinado ${ }^{25}$.

\subsection{Descampesinización/proletarización}

La profundización del capitalismo en el agro salvadoreño condujo a un proceso de descampesinización, es decir, a la disminución de la propiedad familiar 
de subsistencia (que no emplea mano de obra contratada ni necesita completar sus ingresos con trabajo asalariado fuera de la propiedad) y el colonato ${ }^{2 h}$. Sin embargo, como hace notar Segundo Montes, ni el colonato ni la propiedad familiar de subsistencia desaparecen totalmente, lo cual se explica por el sostén socioeconómico que ambas prestan al polo capitalista de la producción agrícola. En efecto, este polo no estrictamente capitalista presta un servicio imprescindible al polo capitalista,

no sólo para producir la mayoría de los alimentos básicos y obtener un 'plusbeneficio' al producir en mejores tierras mientras los campesinos lo hacen en tierras marginales (...), sino que además logran que los campesinos produzcan a base de mucho trabajo los alimentos necesarios $\longrightarrow$ una parte de ellos- y así reproduzcan durante la mayor parte del año su fuerza de trabajo, y solamente les pagarán unos salarios insuficientes para ellos durante los períodos de empleo, obteniendo así una mayor plusvalía ${ }^{27}$.

El proceso que estamos considerando se refleja en los siguientes datos: el número de familias sin tierras en 1961 constituían el 19.8 por ciento del total; en 1971, ese porcentaje se elevó al 31.8 por ciento; y en 1975 , al 41.1 por ciento. Las microfincas, por su parte, han ido disminuyendo: 37.8 por ciento en 1961 ; 33.5 por ciento en 1971 y 27.8 por ciento en 1975 . Las propiedades subfamiliares indican una evolución similar: 35.4 por ciento en 1961; 29.8 por ciento en 1971 y 26.6 por ciento en $1975^{28}$.

Ahora bien, el proceso de descampesinización libera mano de obra apta para trabajar en el polo capitalista del agro salvadoreño. Es decir, el proceso de descampesinización va aparejado a un proceso de proletarización de la mano de obra campesina. ¿Qué supone esa proletarización? Supone -como hace notar Cabarrús- "que haya capacidad para proletarizar y que los campesinos puedan ser contratados como asalariados"2y . En los años setenta, las empresas agrícolas capitalistas no fueron capaces de absorber salarialmente el contingente de mano de obra campesina que el mismo avance capitalista en el agro estaba generando. Así, la tasa total de desempleo agrícola en 1971 fue de 48.8 por ciento, alcanzando en algunos departamentos del país porcentajes mucho más elevados (72.28 por ciento en San Salvador, 59.66 por ciento en Cabañas, 59.83 por ciento en Cuscatlán) $)^{3 \prime \prime}$.

En definitiva, como sostiene Segundo Montes, en el agro salvadoreño efectivamente se generó, durante el período que estudiamos, un proceso de proletarización inducido por la profundización del modo de producción capitalista. "Sin embargo, dice este autor, las plantaciones capitalistas no tienen capacidad de empleo pleno para toda la PEA del sector, fuera de los meses en que se concentra la mayor parte de las cosechas, por lo que no sólo no genera la proletarización consecuente con el incremento de las familias sin tierra y con la depauperación del campesinado que tiene que buscar en el salario un complemento para repro- 
ducir su fuerza de trabajo, sino que también incrementa el ejército de reserva en el campo, que presionará por mantener bajos salarios" ${ }^{\text {311 }}$.

\section{Transformación agraria y organización campesina}

\subsection{El decreto de transformación agraria y la creación del ISTA}

Desde 1932, la sindicalización campesina se convirtió en tema tabú para la oligarquía salvadoreña y para los sucesivos gobiemos militares que controlaron el aparato estatal. La organización de los campesinos no tenía cabida en las leyes, y cualquier voz que apuntara en la dirección de establecer ese derecho era acallada de inmediato, ya fuese con la persuasión de un discurso anticomunista o mediante la violencia física. No fue sino hasta 1976 que un gobiemo, el gobierno del coronel Arturo Armando Molina, tuvo la osadía no sólo de hablar oficialmente de organización campesina, sino de una "transformación agraria"32.

En efecto, en junio de 1976, la Asamblea Legislativa aprobó el "Decreto del Primer Proyecto de Transformación Agraria", a través del cual se establecían modificaciones importantes en el régimen de tenencia de la tierra en los Departamentos de Usulután y San Miguel, en la zona oriental del país ${ }^{33}$. Casi paralelamente a la aprobación del Proyecto de Transformación Agraria, la Asamblea Legislativa aprobó la "Ley de Creación del Instituto Salvadoreño de Transformación Agraria (ISTA)", el cual daba vigencia a la estructura legal e institucional mediante la cual se haría efectiva la transformación agraria ${ }^{34}$.

La creación del ISTA constituía un paso sin precedentes en el horizonte de la organización campesina en El Salvador, sobre todo considerando que se trataba de una iniciativa estatal. En sus artículos 21 y 27, la Ley del ISTA era clara al respecto:

Art. 21. "El ISTA fomentará la organización campesina de acuerdo con su Ley y Reglamentos, especialmente para: a) facilitar en los asentamientos campesinos la prestación de servicios necesarios para la producción tales como: adquisición de insumos, servicios de maquinaria, levantamiento de las cosechas, comercialización y procesamiento de las mismas, a través de una forma asociativa; b) crear una actitud de solidaridad sin cambios, en las obligaciones y riesgos de las empresas agropecuarias y forestales que se establezcan en el proyecto; c) establecer reservas específicas para invertir en el desarrollo de las nuevas actividades económicas del Proyecto, a fin de incorporar al proceso de transformación agraria a un mayor número de familias o para el mejoramiento de los servicios comunitarios que se presten a los campesinos en el área".

Art. 27. "Para la realización de este Proyecto, el ISTA contará con una Unidad Ejecutora, cuyas funciones serán esencialmente las siguientes: a) administración temporal de las tierras del proyecto; b) adecuación de las mismas; 
c) promoción, organización y capacitación campesina; y d) coordinación, en la zona del proyecto, de las actividades que corresponda ejecutar a las instituciones del Estado que participan en el mismo, de acuerdo con la programación correspondiente" 35 .

El Proyecto de Ley de Transformación Agraria presentado por el gobierno del coronel Molina generó una inmediata movilización social en apoyo a la aprobación del mismo, movilización en la que participaron activamente la Universidad Centroamericana "José Simeón Cañas", la Federación Cristiana de Campesinos Salvadoreños (FECCAS) y la Unión de Trabajadores del Campo (UTC), mediante la promoción de seminarios y planteando nuevas propuestas. Por su parte, las presiones del gran capital y de los sectores terratenientes aglutinados en el Frente de Agricultores de la Región Oriental (FARO) se hicieron sentir sobre el gobiemo a través de una campaña que estos sectores realizaron -a través de $\mathbf{L a}$ Prensa Gráfica y El Diario de Hoy - con el fin de hacerlo desistir de sus propósitos reformistas. Al final, la batalla fue ganada por los sectores opuestos a la transformación agraria, ante quienes el gobiemo no tuvo otra opción que decir "a sus órdenes, mi capital" (I. Ellacuría)

Como resultado de la ofensiva oligárquica, en octubre de 1976, la Asamblea Legislativa aprueba el Decreto 123: "Reformas a las Leyes de Creación del Instituto Salvadoreño de Transformación Agraria y del Primer Proyecto de Transformación Agraria", mediante el cual se redefinen aquellos aspectos de las propuestas originales que más afectaban los intereses de los terratenientes ${ }^{37}$.

Con Molina, pues, se aborta un intento de dotar a los trabajadores del campo -desde la esfera estatal - de una serie de derechos económicos, sociales y políticos fundamentales para hacer menos difíciles las condiciones de vida en el agro. Un resorte esencial para la conquista y consolidación de esos derechos era no sólo la transformación de las relaciones de propiedad en el campo, sino el fortalecimiento de la organización campesina.

Aunque colapsado, el intento del gobierno de Molina sentó las bases para que el tabú de la organización campesina dejara de serlo; la urgencia y necesidad de la misma no sólo se había vuelto tema de discusión en diferentes instancias gubernamentales y de la sociedad civil, sino que importantes sectores campesinos habían caído en la cuenta de la legitimidad y posibilidad de dotarse de estructuras organizativas que les permitiesen canalizar sus demandas. Una de las instancias que contribuyeron a esa toma de conciencia campesina -incluso mucho antes del intento del gobiemo del coronel Molina - fue la Iglesia católica salvadoreña que se tomó en serio el problema de la organización campesina y que lo asumió, desde la década de los sesenta, como un desafío pastoral fundamental. 


\section{Iglesia y organización campesina}

\subsection{Consertadurismo eclesial}

La iglesia católica ha tenido un enorme influjo en la realidad histórica salvadoreña no sólo durante la colonia y el período conservador, sino en el período liberal, que se inicia a finales del siglo XIX cuando se produce la revolución liberal y se institucionaliza la República ${ }^{34}$. En este sentido, en el caso salvadoreño no es tan cierta la tesis - sostenida por los liberales - de que la revolución liberal excluyó al poder eclesiástico de la esfera social, económica y poiitica. Por el contrario, la Iglesia "tuvo la flexibilidad suficiente para reubicarse en el nuevo orden económico, social y político" ${ }^{\text {"3y }}$, y se mantuvo como una instancia de poder junto con las otras instancias de poder económico y político que se constituían en el momento del despegue de la república liberal.

El poder eclesiástico se caracterizó, desde finales del siglo XIX hasta los años cincuenta, por el apoyo casi monolítico de las autoridades eclesiásticas al proyecto socioeconómico y político impulsado por la clase gobernante, civil y militar, que se consolidó en el poder durante el primer cuarto del siglo XX. Rodolfo Cardenal - luego de una análisis exhaustivo de los documentos oficiales de la Iglesia - resume así la percepción de la jerarquía eclesial, respecto a la Iglesia, la sociedad, la religión y la política, durante este primer cuarto de siglo:

La Iglesia... tenía una misión dentro de la sociedad. La religión se consideraba obligada a civilizar, moralizar y unir al pueblo. Esta misión se llevaba a cabo mediante la formación de las conciencias. Es decir, la función social de la Iglesia estaba reducida al ámbito de la conciencia. En ella se daba el punto de coincidencia entre las dos esferas, lo político y lo religioso. En virtud de esta función social el Estado estaba obligado a reconocer oficialmente a la religión y a protegerla. A su vez, la religión colaboraría enormemente en la conservación del orden establecido evitando los cambios radicales. La religión se presentaba a sí misma como una garantía contra el odio del pueblo. Su fuerza estaba en la formación de las conciencias la cual consistía en interiorizar en las conciencias de los ciudadanos el respeto y la veneración a las autoridades constituidas. Además, por medio de su labor uniría al pueblo con vínculos internos y permanentes garantizando el orden y la paz, condiciones indispensables para el progreso en que estaba empeñado el gobierno ${ }^{41}$.

Si el compromiso con las autoridades constituidas por parte de la Iglesia era así de decidido, no era menos decidido su rechazo al socialismo y el comunismo. En 1927, el entonces Administrador Apostólico de la Arquidiócesis de San Salvador y futuro Arzobispo, Mons. Alfonso Belloso, emitió una Carta Pastoral titulada "El presente momento social", documento en el cual se resume la postura de la Iglesia ante la doctrina socialista ${ }^{41}$. Pero el documento no tiene una finalidad meramente doctrinal, sino que su finalidad última es política: a través 
del mismo la jerarquía eclesial desaprueba y condena el influjo del movimiento comunista en la coyuntura de la época. En un apartado de la Carta Pastoral de Mons. Belloso, titulado "El socialismo y la patria salvadoreña", se puede leer lo siguiente:

El socialismo, así como aborrece las ideas de la propiedad familiar, estado, religión, así también abomina la idea de Patria. Las fronteras se le antojan coacción y tiranía, y ha jurado borrarlas; el hombre ha de ser ciudadano del universo; en el mundo socialista no habrá naciones, habrá sindicatos. Por consiguiente, en la geografía socialista no contará la República de El Salvador, sino la Confederación de Camaradas Salvadoreños ${ }^{42}$.

Al referirse a los problemas nacionales, Mons. Belloso continúa diciendo:

Confiar la solución de problemas tan complejos y espinosos a mitines populares y a conferencias tendenciosas — por más que se adoren con los nombres de centros culturales y campañas contra el analfabetismo- sería reconocido desacierto.

No necesitamos agrupaciones propagandísticas que lancen a los cuatro vientos ideas inspiradas por el comunismo extranjero, sino Círculos de Estudios que, de la observación directa de nuestra vida social íntima, infieran las causas y los remedios de sus dolencias.

Invitamos, pues, a todos los intelectuales salvadoreños a esta labor tranquila y de veras provechosa... proponiéndoles para nuestra mutua inteligencia el siguiente criterio: El sistema económico social más aceptable es el que mejor concilia el mayor bien posible del individuo con el mayor bien posible de la colectividad ${ }^{4}$.

Esa conciliación suponía rechazar cualquier intento de reforma del modelo socioeconómico y político establecido. Y como este modelo se fundaba en cl control sobre la tierra ejercido por un grupo de propietarios de las grandes haciendas cafetaleras, lo más temido era justamente la transformación de las relaciones de propiedad en el agro. El levantamiento campesino de 1932 se constituyó en una amenaza para la dominación de los grupos oligárquicos. Pero no sólo el ejército y los grupos paramilitares de la oligarquía lo enfrentaron, sino también la Iglesia. Controlado el alzamiento campesino, su amenaza quedó presente como un fantasma para los grupos de poder. Reforma agraria y organización campesina fueron temas innombrables para la élite dominante desde 1932.

Las autoridades eclesiásticas hicieron eco de esta demanda de los grupos de poder durante más de 30 años. Así, mientras que a nivel pastoral extensas zonas del agro salvadoreño no tuvieron una atención adecuada (que muchas veces fue inexistente), a nivel doctrinario se propagó una interpretación extremadamente conservadora (interiorista y piadosa) del mensaje cristiano. Los ejes de esta interpretación eran, primero, que los fieles tenían que preocuparse, ante todo, por 
la salvación de su alma, lo cual suponía llevar una vida moral recta; y, segundo, que los fieles tenían que aceptar y respetar el orden (político, económico y social) comd un designio divino. En lo político, este designio era sancionado religiosamente con un Te Deum organizado por la jerarquía eclesial para bendecir el inicio de cada nuevo gobierno ${ }^{44}$. En lo económico, los nexos de las autoridades eclesiásticas con los grupos dominantes eran estrechos; y los mismos se hacían sentir no sólo en las prebendas económicas que estos grupos ofrecían a la Iglesia, sino en las presiones en favor o en contra de una determinada orientación eclesial ${ }^{45}$.

\subsection{Giro eclesial: cooperativismo y organización política}

Hacia finales de la década de los cincuenta, la opción eclesial tradicional comienza a sufrir una serie de modificaciones, inducidas no sólo por el influjo del ambiente generado por las discusiones y los preparativos del Concilio Vaticano II -a la que no son ajenos sectores importantes del clero salvadoreño, entre los que destacan los jesuitas - o por el influjo del compromiso de muchos cristianos latinoamericanos simpatizantes de la revolución cubana, sino por factores endógenos, socioeconómicos, políticos y religiosos, que exigían a la institución eclesial replantearse su pastoral social.

Estos factores son los siguientes: (a) la exclusión política de importantes sectores de la sociedad civil, incompatible con el modelo económico de carácter desarrollista que impulsa la burguesía industrial; (b) el atraso y la marginación campesinas, que -de no ser atendidas - anuncian un conflicto de incalculables consecuencias; y (c) la escasa o nula atención eclesial a la población mayoritaria del país que se confiesa católica, y que amenaza con desbordarse hacia el protestantismo.

Es así como, durante los años sesenta, la Iglesia católica salvadoreña busca acercarse eficazmente al campo y lo hace promoviendo formas de organización cooperativa $^{46}$. El promotor de esta pastoral de inserción eclesial en el campo fue el entonces Arzobispo de San Salvador, Mons. Luis Chávez y González. Hasta finales de la década, esta orientación pastoral va a estar caracterizada en lo esencial por el patemalismo y el asistencialismo ${ }^{47}$. Sin embargo, a fines de los sesenta y principios de los setenta, el modo de enfocar el problema de la organización campesina comenzó a cambiar hasta que se transformó en algo totalmente alejado de los planteamientos tradicionales. Este viraje eclesial estuvo muy condicionado - y de algún modo respondió- a los retos que lanzó a la Iglesia católica salvadoreña el Episcopado Latinoamericano reunido en Medellín, en 1968.

Así, el compromiso eclesial, entre los años sesenta y setenta, transita -fundamentalmente en la Arquidiócesis de San Salvador- desde un apoyo a la organización campesina de naturaleza paternalista y asistencial (que se expresa en el fomento de asociaciones cooperativas) hasta el compromiso decidido de sacer- 
dotes, religiosas y religiosos y del propio Arzobispo de San Salvador, en respaldo de las demandas autónomas (sociales, económicas y políticas) de las organizaciones campesinas ${ }^{48}$.

\subsection{La reacción conservadora}

No toda la Iglesia católica asumió los desafíos en torno a la nueva evangelización que Medellín promovióo ${ }^{4}$. Pero una buena parte de ella -cercana a la Arquidiócesis de San Salvador, dirigida hasta 1977 por Mons. Chávez y González y desde ese año hasta el 24 de marzo de 1980 por Mons. Oscar A. Romero-sí lo hizo y con una radicalidad que pronto comenzó a provocar el resquemor no sólo del gobiemo y de los sectores económicamente dominantes, sino de sectores importantes de la jerarquía eclesial ${ }^{510}$. Como ejemplo de la reacción de estos sectores de la jerarquía eclesial se puede traer a cuenta la "Declaración de cuatro Obispos de la Conferencia Episcopal de El Salvador", en la que los mismos manifestaron su crítica y rechazo tanto a la orientación política de las organizaciones FECCAS-UTC, como a cualquier tipo de compromiso de miembros de la Iglesia con aquéllas. Entre otras cosas, la "Declaración" dice lo siguiente:

La Federación Cristiana de Campesinos Salvadoreños (FECCAS), nació como organización reivindicadora de los derechos de los campesinos; pero muy pronto, al derivar al campo político, buscando la toma del poder y al coaligarse con la Unión de Trabajadores del Campo (UTC); y, sobre todo, al afiliarse con el Bloque Popular Revolucionario (BPR), se declararon ambas seguidoras de la ideología marxista-leninista.

La actitud proselitista de dichas organizaciones se infiltró en algunos grupos de fieles de la Iglesia, creando confusión entre los católicos y un serio problema de conciencia...

Nosotros los Obispos, en cumplimiento de Nuestro Ministerio Pastoral, declaramos que las organizaciones de tipo político y de tendencia izquierdista conocidas como Federación Cristiana de Campesinos Salvadoreños (FECCAS) y Unión de Trabajadores del Campo (UTC) no son organismos de la Iglesia y, por consiguiente, no tienen derecho a reivindicar para sí la protección de la Iglesia o quererla instrumentalizar para sus fines.

Los sacerdotes y religiosas que dirigen centros educativos y comunidades parroquiales deben abstenerse de colaborar directa o indirectamente con FECCAS y UTC y con cualesquiera otras organizaciones similares, cuya actividad se desarrolla en el campo directamente político (la toma del poder), y porque, además, son organizaciones de izquierda.

Los seglares católicos, responsables de llevar el Mensaje de Cristo al campo social, político, cultural, eviten valerse para su obra evangelizadora de las organizaciones FECCAS y UTC ${ }^{51}$. 
Y como ejemplo de la reacción de la oligarquía es ilustrativo el comunicado emitido en el periódico La Prensa Gráfica por el Frente de Agricultores para la Región Oriental (FARO), el 31 de marzo de 1977. En el mismo se cita el siguiente fragmento de la misa oficiada el domingo 22 de marzo en la Catedral de San salvador:

La Iglesia cree en Dios, Creador, en Jesucristo Redentor y en Espíritu Santo Santificador. La Iglesia cree QUE EL MUNDO ESTÁ LLAMADO A SER SOMETIDO A JESUCRISTO POR UNA PAULATINA INSTAURACIÓN DEL REINO DE DIOS. Cree la Iglesia en la Comunión de los Santos y en el amor que une a los hombres. CREE EN EL REINO DE DIOS COMO PROGRESIVO CAMBIO DEL MUNDO DEL PECADO EN MUNDO DE AMOR Y JUSTICIA, que comienza YA en este mundo y tiene su cumplimiento en la eternidad.

Inmediatamente después de citado este texto, el documento del FARO hace el siguiente señalamiento:

FARO no tiene la intención, igual que otras veces, de incurrir en discusiones teológicas como serían: si es válido CREER EN EL HOMBRE, EN EL SOMETIMIENTO DEL MUNDO A JESUCRISTO Y EN EL PROGRESIVO CAMBIO DEL MUNDO, COMO UN CREDO, COMO UN DOGMA, EN IGUALDAD DE CATEGORÍA QUE EL DOGMA DE DIOS PADRE, DE CRISTO HIJO ÚNICO DE DIOS Y DEL ESPÍRITU SANTO, porque esas CUESTIONES DE LA FE corresponden a las más altas autoridades eclesiásticas que están en ROMA.

En Cambio, FARO tiene derecho a hacer pública su INDIGNACIÓN Y HACER VER A TODOS LOS CATÓLICOS QUE UNA ORACIÓN TAN IMPORTANTE COMO ES EL “CREDO" HA SIDO SUSTITUIDA POR OTRA NETAMENTE POLÍTICA-SOCIAL, PUES ÉSTE ES EL VERDADERO SIGNIFICADO DEL CONTENIDO DEL "NUEVO CREDO". FARO le dice "NO" al Señor Arzobispo, NO ADULTERE LA RELIGIÓN, SUS ORACIONES FUNDAMENTALES, SU DOGMÁTICA. Y a la vez pide a Roma su intervención para que TERMINE ESA LABOR POR POLITIZAR LA RELIGIÓN E IGLESIA CATÓLICAS ${ }^{52}$.

Finalmente, en un documento aparecido como volante anónimo, la reacción de los sectores dominantes se manifiesta con mayor virulencia. El volante está encabezado con la siguiente frase: "Romero celebra misa-mitin", y a continuación dice lo siguiente:

El Arzobispo de San Salvador Amulfo Romero, que preside en estos momentos la Iglesia política, celebró una misa mitin, en corredores y patios del Colegio María Auxiliadora de San Salvador, el 9 de julio de 1977. Romero, que antes era sacerdote católico, pero ahora actúa como agitador profesional, 
haciéndoles el 'cachete's3 a las organizaciones marxistas... EXPRESÓ QUE LA IGLESIA ES PERSEGUIDA, pero no dijo que 'su Iglesia política' ahora protege a organizaciones marxistas incluyendo a los 'pobres perseguidos de las FPL'...

Habló de los documentos de Medellín, donde cierto grupo de Obispos de vocación equivocada, decidieron que la orientación espiritual del hombre era muy aburrida y que sería mejor lanzarse a la corriente mundana. El único problema para estos buscadores de placer y de aventuras es que en la corriente mundana nadan peces de otras especies, tales como los 'UGB's4 que los pueden devorar, al encontrarlos fuera de sus conventos ${ }^{35}$.

\subsection{La experiencia de Aguilares}

En Aguilares es en donde con mayor nitidez se hizo presente esta "nueva lectura" del mensaje cristiano. Esta zona rural —n la perspectiva de los sacerdotes y religiosos involucrados con la opción preferencial por los pobres y la teología de la liberación - era clave para una nueva experiencia pastoral porque expresaba las múltiples contradicciones que aquejaban al agro salvadoreño. En 1972 - señala C. R. Cabarrús-, estos sacerdotes y religiosas se lanzaron a la tarea evangelizadora, misma que supuso la inserción, durante casi un año, de aquéllos en los diversos cantones, así como su convivencia con la población campesina, "comiendo lo que se les daba, aceptando cualquier incomodidad para construir la comunidad desde abajo y no por imposición"sh.

De este modo, la misión logró, estructurar la masa campesina y urbana cohesionando la gran comunidad en comunidades dirigidas o más bien animadas por un grupo en el que prevalecen unos hombres dirigidos por la comunidad al final de la misión: son los 'delegados'. No era propiamente una directiva, porque de cada cuatro o cinco personas se elegía un delegado, y pudieron llegar a ser hasta 15 ó 20 delegados por comunidad. En total fueron 300 delegados los que aceptaron como principio el que todo cargo debe ser mirado como servicio y no como dominación, a fin de buscar con los demás 'la verdad, la unión, la acción, la organización', como decían ${ }^{57}$.

En estas comunidades, animadas en un principio por los sacerdotes y posteriomente por los delegados de la palabra, se leía el Evangelio a la luz de la situación real que vivían cotidianamente los campesinos. Como señala C. R. Cabarrús, "los ojos de la gente se abren al Evangelio y aprenden a unirlo con su situación, a 'traerlo de lo espiritual a lo material', según manifestaban. Despiertan a la conciencia de que la situación de opresión en que viven no es voluntad de Dios y de que muchos males vienen 'por no ser unidos'. Comienzan a reunirse, a movilizarse y a ver qué es lo que pueden hacer. La meta pretendida por el equipo misionero es la de 'realizar una comunidad de hermanos comprometidos a construir un mundo nuevo sin opresores ni oprimidos, según el plan de Dios"'58. 
Progresivamente, esta dinámica pastoral fue posibilitando una mutación religiosa en la conciencia de los campesinos involucrados en el proceso. C. R. Cabarrús, quien vivió directamente este proceso sostiene que

antes de la llegada de las misiones con las que se abrió el trabajo pastoral, el munde 'religioso' del campesino de Aguilares estaba caracterizado por las típicas notas de una ideología religiosa campesina, es decir, enmarcadas en un sistema por el cual el campesino es explotado por el capital, pero él mismo es el agente directo de dicha explotación. Esto lo hace mistificar esa explotación que casi no percibe ni por la vía del salario, ni por la vía del precio de los productos, ni por la renta de la tierra. Debe agregarse la misma trabazón con lo 'rural' y con la agricultura, que imprime un carácter peculiar a su manera de pensar y valorar: los códigos interpretativos hacen siempre relación con las estaciones y las cosechas ${ }^{54}$.

Para un campesino de Aguilares:

con la misión hubo un cambio. Desde la misión, en los quince días hubo una gran movilización; bajaba gente de todas partes a Areditas. Entonces hubo una gran movilización y quedó la cosa más en orden. Se formaron grupo de delegados que decían que habían unos explotadores y otros explotados. Se comenzó a descubrir la situación real.

De ahí vimos la necesidad de ir protestando, aunque no nos habíamos organizado ni nada... vimos que no era simplemente necesario la organización, sino una verdadera urgencia. Allí comenzó a meterse la organización en la zona $a^{(x)}$.

Pero, con el trabajo de la misiones, la religiosidad campesina - como ya lo señalamos- se va transformando progresivamente. La idea de Dios como causa única e irreversible de los acontecimientos lentamente es reemplazada por la idea de un Dios que actúa en la historia no a espaldas de los hombres, sino a través de éstos. Es esto lo que aparece con claridad en el siguiente testimonio de un campesino de Aguilares: "yo creo en un Dios de justicia y amor y paz, y no en un Dios que esté en las nubes, que está en el corazón de los explotadores, en un Dios de la explotación, en un Dios convertido en pisto (dinero), en un Dios convertido en propaganda, ni en un Dios que se le agrade con cohetes, ni con ceremonias tradicionales ${ }^{\text {hl }}$.

El mismo campesino continúa más adelante en su relato:

para mí, Jesucristo es nuestro guía, es un líder que nos dio suficiente ejemplo con su vida. Estuvo a favor de los pobres, exigió que se cumpliera la justicia, el amor, la comprensión y la paz. Se mostró bien serio con los poderosos que explotaban al pueblo. Convenció a los duros de corazón, derribó a los poderosos de sus tronos, y en todo momento estuvo a favor de los pobres. Es el primer hombre al que yo obedezco y quiero seguirle hasta dar mi vida si es preciso ${ }^{\text {h2 }}$. 
Para otro campesino incluso la violencia contra los que le oprimen encuentra su legitimación en el Evangelio:

Al pueblo de Israel, Dios mismo lo hizo que hiciera matazones; Dios mismo utilizó la violencia para destruir el mal ${ }^{63}$.

$Y$ del mismo tenor es este otro relato:

Moisés empezó como nosotros. Vemos a alguien que está sufriendo y dan ganas de matar. Pero a veces vale la pena. Como Moisés, él lo mató y iqué le pasó? tuvo que huirse. Nada hacemos solitos. Sólo, quizás, nada voy a hacer; pueda pasarme igual que a Moisés. El pasó varios años humillándose. Por eso primero hay que hacer conciencia ${ }^{\text {t4 }}$.

En definitiva, en la conciencia de estos campesinos se gesta un proceso de conversión religiosa que les llevó, de una visión religiosa cuasi fatalista, hacia una visión religiosa "liberadora", en el sentido de haberles hecho pensar en Dios como en un Dios de justicia y de libertad. Como lo sintetiza T. S. Montgomery: "el nuevo mensaje era: 'Dios es un Dios de justicia que actúa en la historia a favor de los pobres y oprimidos. La pobreza de ustedes no es voluntad de Dios... De la misma manera que Moisés y los israelitas asumieron el reto de su liberación, ustedes tienen derecho para asumir la responsabilidad de su propia liberación...' Y la Iglesia tiene la obligación de acompañarlos en el proceso" ${ }^{\text {as }}$.

Y así, esta evangelización pronto reveló sus implicaciones políticas, pues en el marco de la violencia estructural sufrida por los campesinos salvadoreños, la religiosidad defendida por Medellín y Puebla planteaba tareas bien concretas, que tenían que ver directamente con el problema de la concientización y la organización política. Los campesinos involucrados en el proceso así lo entendieron: asumieron su dignidad de hijos de Dios dándose formas organizativas que les permitieran luchar por conquistar una vida más humana ${ }^{\text {ats }}$.

\section{El agro salvadoreño en la década de los ochenta: reforma agraria y cooperativismo}

El rasgo más distintivo del sector agropecuario durante la década de 1980 fue, sin duda, la implementación de la reforma agraria, la cual intentó trastocar los elevados niveles de concentración de la tierra en El Salvador, aunque con poco éxito. En principio, la reforma agraria pretendió ser desarrollada en tres fases de las cuales solamente fueron implementadas dos, la primera y la tercera.

Las tierras afectadas por las diferentes fases reunían las siguientes características: la fase I contemplaba la expropiación de tierras con una extensión superior a las 500 hectáreas (ha), lo cual implicaba afectar un 15 por ciento de la tierra agrícola ${ }^{\text {67; }}$ la fase II incluía la expropiación de aquellas tierras con una extensión de entre 150 y 500 ha, que abarcaba el 23 por ciento de la tierra agrícola ${ }^{68}$; finalmente la fase III contempló la asignación de tierras para los tenedores de 
parcelas no mayores de 7 ha, lo cual de acuerdo con datos of iciales comprendió cerca del 4 por ciento de las tierras agrícolas ${ }^{69}$.

La primeła fase de la reforma agraria implicó la creación de nuevas cooperativas agropecuarias que vinieron a sumarse al cooperativismo tradicional, aunque con determinismos muy diferentes. El estilo de cooperativismo que surgió de la reforma agraria tuvo que lidiar con condicionantes políticos, económicos y administrativos que provocaron desequilibrios financieros en las cooperativas, lo cual, para finales de la década de 1980, fue utilizada por el gobiemo de Alfredo Cristiani para promover la disminución de las formas cooperativas de propiedad. En lo que sigue de este apartado se analizarán algunos indicadores del desempeño económico de las cooperativas, el contexto crediticio de las mismas y algunos rasgos característicos de la política estatal hacia el sector para intentar aclarar las verdaderas causas de la crisis del cooperativismo en el sector reformado.

\subsection{La evolución del sector cooperativo de la reforma agraria}

Uno de los argumentos más utilizados por el gobiemo de Cristiani para evaluar el proceso de reforma agraria y atacar el cooperativismo fue la disminución de la producción y el incremento de las áreas sin utilizar que se suscitó en la década de 1980. Sin embargo, esta valoración soslaya la importancia de considerar cuáles han sido las causas de la caída de la producción en el sector reformado; más aún no considera que la crisis del sector reformado se circunscribió dentro de la crisis general del sector agropecuario ${ }^{70}$. Como se trata de mostrar a continuación, la evolución del sector reformado no necesariamente refleja que el cooperativismo no sea una forma viable de producción, sino más bien la inexistencia de políticas complementarias de apoyo al sector reformado. Prueba de lo anterior es el comportamiento del crédito y la productividad de este sector.

\subsection{Uso del suelo (1981-1990)}

De acuerdo con datos obtenidos de la Oficina Sectorial de Planificación Agropecuaria (OSPA), la utilización de la tierra en las cooperativas del sector reformado ha cambiado sustancialmente durante la década de 1980; en especial por la caída de la participación del área destinada al cultivo de alimentos, el incremento del área de cultivos de exportación y, sobre todo, por el incremento de la categoría "otros".

Como muestran los datos del Cuadro 1, el cultivo de granos básicos descendió su utilización del 18.18 por ciento del total de las tierras en manos de cooperativas de la reforma agraria en el año agrícola 1981/82 a sólo el 6.77 por ciento del mismo total para el año 1989/90; en contraparte, los cultivos de café y caña de azúcar incrementaron su extensión de 12.61 y 7.30 por ciento, respectivamente en $1981 / 82$ a 13.51 y 10.23 por ciento en $1989 / 90$. Sin embargo, debi- 
do al abandono del cultivo del algodón, los productos de exportación disminuyeron en conjunto su participación en la utilización de la tierra.

\section{Cuadro 1}

Distribución de la tierra utilizada según cultivos (en porcentajes)

\begin{tabular}{lrrrr}
\hline & $1981 / 82$ & Porc. & $1989 / 90$ & \multicolumn{1}{c}{ Porc. } \\
\hline Total área cultivada & 86783 & 57.63 & 88,857 & 57.07 \\
Maíz & 16047 & 10.65 & 5707 & 3.66 \\
Frijol & 4240 & 2.82 & 2701 & 1.74 \\
Arroz & 4108 & 2.73 & 483 & 0.31 \\
Maicillo & 2985 & 1.98 & 1681 & 1.08 \\
Total granos básicos & & 18.18 & & 6.77 \\
Café & 18992 & 12.61 & 21026 & 13.51 \\
Caña & 11006 & 7.30 & 15925 & 10.23 \\
Algodón & 19095 & 12.68 & 4605 & 2.96 \\
Productos exportación & 10310 & 6.86 & 36,729 & 23.60 \\
Otros & & & & \\
& 33990 & 22.57 & 41897 & 26.91 \\
Área total de pastos & & & & \\
& 29807 & 19.79 & 24917 & 16.00 \\
Área de bosques & 150580 & 100.00 & 155671 & 100.00 \\
Total & & & & \\
\hline
\end{tabular}

Fuente: Elaboración propia con base en datos de OSPA, 1982, Anexo II-3 y OSPA, 1991, p. 37.

Las dinámicas anteriores se explican principalmente por el incremento del área dedicada a "otros" cultivos y el área de pastos, los cuales pasaron de 6.86 y 22.57 por ciento, respectivamente, en 1981/82, a 23.60 y 26.91 por ciento, respectivamente, en 1989/90. Obviamente, el mayor incremento se ha suscitado en el rubro de "otros", sin embargo, aún resta por constatar si en realidad el incremento de este rubro no ha sido resultado del abandono y/o subutilización de tierras.

Cabe mencionar que el área de bosques en el sector reformado también disminuyó durante la década de 1990 , lo cual ha venido a contribuir a la dinámica de agotamiento de los recursos naturales y deterioro de las condiciones ambientales. En términos absolutos se calcula que la extensión de bosques se redujo en aproximadamente 5000 ha (Cuadro 1). 


\subsection{Producción y productividad}

En consopancia con el comportamiento de la utilización de la tierra, la producción del sector reformado durante la década de 1980 revela una disminución en la producción de alimentos y un incremento en la producción de cultivos tradicionales de exportación, en especial café y caña de azúcar. Contrariamente a lo que podría esperarse, la productividad o rendimiento de los cultivos se ha incrementado durante el mismo período, lo que ha revelado que la caída de la producción obedece primordialmente a la disminución del área cultivada.

\section{Cuadro 2}

Producción y rendimiento de los principales cultivos cooperativas del sector reformado

\begin{tabular}{|c|c|c|c|c|}
\hline & \multicolumn{2}{|c|}{$1981 / 82$} & \multicolumn{2}{|c|}{$1989 / 90$} \\
\hline & $\begin{array}{l}\text { Prod. } \\
\text { (qq) }\end{array}$ & $\begin{array}{l}\text { Rend. } \\
\text { (qq/ha) }\end{array}$ & $\begin{array}{l}\text { Prod. } \\
\text { (qq) }\end{array}$ & $\begin{array}{l}\text { Rend. } \\
\text { (qq/ha) }\end{array}$ \\
\hline \multicolumn{5}{|l|}{ Granos básicos } \\
\hline Maíz & 799700 & 39.20 & 366638 & 64.20 \\
\hline Arroz & 300113 & 51.12 & 208972 & 77.40 \\
\hline Frijol & 90784 & 15.00 & 7025 & 14.50 \\
\hline Maicillo & 91470 & 23.87 & 48937 & 29.10 \\
\hline \multicolumn{5}{|l|}{$\begin{array}{l}\text { Tradicionales de } \\
\text { exportación }\end{array}$} \\
\hline Café & 439970 & 16.20 & 382696 & 19.80 \\
\hline Caña de Azúcar (TC) & 878968 & 60.86 & 1276671 & 102.90 \\
\hline Algodón & 854420 & 31.30 & 171518 & 37.20 \\
\hline
\end{tabular}

Fuente: OSPA, 1982, p. 24, y OSPA, 1991, p. 78.

A excepción del cultivo de frijol, los principales cultivos del sector reformado experimentaron una clara mejoría en sus niveles de productividad (Cuadro 2), lo cual lamentablemente no impidió que se suscitara una pronunciada disminución en la producción de todos los cultivos, menos la caña de azúcar cuya producción mostró una tendencia creciente.

La productividad del sector reformado se incrementó a lo largo de la década, inclusive por arriba del nivel observable en las explotaciones que no fueron afectadas por la reforma agraria, tal como lo evidencia el hecho de que los rendimientos del sector reformado fueron mayores que los correspondientes al nivel nacional" . Los datos del Cuadro 3 muestran que para el año agrícola 1989/90, los cultivos de maíz, maicillo, algodón y caña de azúcar ofrecían ma- 
yores rendimientos en el sector reformado que a nivel nacional. El cuadro en cuestión también revela que para principios de la década de 1980, sólo el arroz y el algodón se producían con mayor eficiencià en el sector no reformado.

\section{Cuadro 3}

Comparación de la productividad entre el sector reformado y el nivel nacional

\begin{tabular}{lcccc}
\hline Rubros & \multicolumn{2}{c}{$1981 / 82$} & \multicolumn{2}{c}{$1989 / 90$} \\
& N.N. & S.R. & N.N. & S.R. \\
\hline Maíz & 27.50 & 39.20 & 46.30 & 64.20 \\
Frijol & 11.72 & 15.00 & 15.10 & 14.50 \\
Arroz & 55.00 & 51.12 & 89.10 & 77.40 \\
Maicillo & 17.90 & 23.87 & 27.10 & 29.10 \\
Café & 11.50 & 16.20 & 19.30 & 19.80 \\
Algodón & 34.00 & 31.30 & 34.40 & 37.20 \\
Caña & 81.00 & 60.86 & 77.20 & 102.90 \\
\hline
\end{tabular}

N.N.: Nivel nacional.

S.R.: Sector reformado.

Fuente: OSPA, 1982, p. 29, y OSPA, 1991, p. 82.

Llama la atención el caso del cultivo de la caña de azúcar en las cooperativas de la reforma agraria, pues, además de haber incrementado el área que ocupa, también tuvo un descollante incremento en sus niveles de rendimiento que lo llevó a superar ampliamente el nivel nacional, pese a que a principios de la década era bastante inferior.

\subsection{Empleo}

La situación del empleo en el sector reformado se encuentra en clara consonancia con el comportamiento de la producción, es decir que ha experimentado una marcada disminución. De acuerdo con los datos del Cuadro 4, para el año agrícola 1989/90 se estimaba que el empleo generado en el sector reformado se había reducido en un 25.42 por ciento en relación con el porcentaje que tuvo en 1981/82. 


\section{Cuadro 4 \\ Empleo generado por las cooperativas del sector reformado (jornales)}

\begin{tabular}{lrrr}
\hline Rubros/año agrícola & $1981 / 82$ & $1989 / 90$ & Variación (\%) \\
\hline Maíz & 1193244 & 449261 & $(62.34)$ \\
Frijol & 363780 & 34298 & $(90.57)$ \\
Arroz & 352440 & 254351 & $(72.16)$ \\
Maicillo & 153648 & 75309 & $(50.98)$ \\
Subtotal & 2063112 & 813219 & $(60.58)$ \\
Café & 4888440 & 4058631 & $(16.97)$ \\
Algodón & 2457450 & 723338 & $(70.56)$ \\
Caña de Azúcar & 1101660 & 1561152 & 41.71 \\
Subtotal & 8447550 & 6343121 & $(24.91)$ \\
Otros & 729500 & 1034347 & 41.78 \\
Pecuario & 1281610 & 1148038 & $(10.42)$ \\
Total & 12521772 & 9338725 & $(25.42)$ \\
\hline
\end{tabular}

Fuente: OSPA, 1982, p. 46, y OSPA, 1991, p. 257.

Las disminuciones más drásticas, empero, han sido las experimentadas por el sector productor de granos básicos, que entre 1981/82 y 1989/90 tuvieron una contracción del 60.58 por ciento en el nivel de empleo generado. Dentro de este rubro, las caídas más significativas del empleo han tomado lugar en los cultivos de maíz y frijol que en conjunto implicaron una reducción de más de un millón de jomales.

Los únicos cultivos que registraron incrementos en la generación de jornales fueron el de la caña de azúcar y el de "otros", que en conjunto se incrementaron en más de 750000 jornales. Sin embargo, ello no fue suficiente para que la generación global de empleo en el sector reformado decayera en más de tres millones de jornales.

\section{La problemática del crédito agropecuario y el cooperativismo}

La dinámica descrita en el apartado anterior mostraría que, pese a la intencionalidad de la fase I la reforma agraria, las cooperativas provocaron una reducción de la producción y del empleo agropecuario y, por tanto, no merecen ser consideradas como una alternativa viable para fomentar el desarrollo del agro. Aparejada a la reforma agraria se suscitaron diferentes situaciones que atentaron contra el éxito del proceso, a saber: mala administración del sector cooperativo, asignación de tierras improductivas, baja asistencia técnica y crediticia, etc. 
Esta situación es tal que después de realizada la reforma agraria, aunque se reportó mejoría en la distribución del ingreso y la propiedad de la tierra, persistieron problemas estructurales tales como "el uso indebido y/o ineficiente del suelo, la heterogeneidad estructural y la ineficiencia productiva"72.

Entre los problemas más serios del sector agropecuario puede mencionarse el del crédito, pues fue uno de los factores que explicaron mejor la situación actual de las cooperativas ${ }^{73}$, especialmente si se considera que el crédito está relacionado de manera directa con la capacidad de inversión y de producción. El crédito al sector agropecuario experimentó una marcada disminución, tanto durante la década de 1980 como en la de 1990. En cuanto al crédito para el sector reformado, la situación fue todavía más grave, pues este sector tuvo menos acceso al crédito que el sector no reformado. De acuerdo con información del Banco Central de Reserva, el crédito al sector agropecuario se redujo de manera sistemática a partir de la década de 1970 y llegó a tal grado, que de recibir el 36.75 por ciento del total del crédito en $1961^{74}$ llegó a obtener sólo el 13.4 por ciento en 1995.

En este contexto se ubicó la implementación de la reforma agraria y lo que, en gran medida, explica también los problemas que se generaron con su funcionamiento. Una evaluación, aún superficial, del crédito hacia el sector reformado muestra que las cooperativas no contaron con los fondos adecuados para hacer frente a los requerimientos mínimos de operación e inversión de las empresas agropecuarias que les fueron encomendadas, ni siquiera en los momentos en que la banca fue nacionalizada y el crédito se asignaba bajo criterios políticos ${ }^{75}$.

Esta situación se ha visto favorecida por el proceso de reprivatización de la banca, lo cual provocó una reorientación del crédito desde el sector agropecuario hacia sectores terciarios. Tal como se señalaba cuando se iniciaba el proceso de reprivatización de la banca:

... los créditos otorgados por el BFA son sólo una parte minoritaria del total otorgado al sector reformado, y el hecho de que estén aflorando denuncias de parte de las organizaciones coooperativas sugiere que la asistencia crediticia a este sector disminuirá sensiblemente, puesto que, sumada a la política asumida por el BFA [reducción de créditos], la privatización de la banca se convertirá en nueva cortapisa para la obtención de créditos por parte del sector cooperativo ${ }^{76}$.

\section{La política gubernamental hacia el sector reformado}

La promoción de la tenencia de la propiedad privada individual en el sector afectado por la reforma agraria ha sido una de las preocupaciones más evidentes de las instituciones oficiales relacionadas con la actividad del sector agropecuario, aunque no precisamente porque se le considere una forma de combatir la pobre- 
za rural, sino más bien porque existen argumentos ideológicos en contra del sector cooperativo. Aunque la producción del sector cooperativo de la reforma agraria haya disminuido y aún persistan las condiciones estructurales originales, es imposible negar que han existido factores que han impedido que el cooperativismo de todo de sí.

En este escenario se ubica la aprobación, en abril de 1991, de la Ley del Régimen Especial del Dominio de las tierras comprendidas en el proceso de Reforma Agraria y más recientemente la condonación de la deuda agraria. Aunque no se trata de entrar en el análisis de estas medidas, sí interesa revisar las implicaciones de la introducción de la forma de propiedad individual dentro de las cooperativas de la reforma agraria, pues ello permite forjarse una idea de la política gubernamental hacia el cooperativismo.

Mediante la ley mencionada arriba se institucionalizó la existencia de tres formas de propiedad privada en las cooperativas del sector reformado: cooperativa de participación real, individual y una forma que combina las dos anteriores. Es decir que la intencionalidad principal es facilitar el camino para la propiedad individual.

Aún antes de la aprobación de la mencionada ley, ya existía una política oficial bien definida en tomo a la forma de propiedad que debía promoverse en el sector reformado. La Financiera Nacional de Tierras Agrícolas (FINATA) ha venido desarrollando desde hace varios años una política de adjudicación de títulos de propiedad individual para beneficiarios del proceso de reforma agraria y, adicionalmente, para la cosecha 1989/90 se implementó en el sector reformado un plan piloto con el que se pretendió explorar las posibilidades de las formas de propiedad individual en este sector rural.

De acuerdo con datos del mismo gobierno, esta iniciativa habría tenido gran acogida dentro del sector cooperativo, al grado que de acuerdo a datos proporcionados por la Secretaría Nacional de Comunicaciones, el 57 por ciento de las cooperativas comprendidas en la primera etapa de la reforma agraria se habrían pronunciado por adoptar una forma de propiedad privada en cualquiera de las tres formas que la ley establecía. El restante 43 por ciento - se afirma- habría optado por continuar explotando sus parcelas bajo formas colectivas de propiedad. Tal situación representa un cambio cuantitativo importante, puesto que de acuerdo con la información del Ministerio de Agricultura y Ganadería (MAG), publicados en la $X$ Evaluación del Proceso de Reforma Agraria, para 1990 sólo el 15 por ciento de las cooperativas comprendidas en la primera etapa de la reforma agraria, que habían sido censadas, expresaron la intención de modificar su forma de ejercer la propiedad de las tierras.

Lo anterior resulta paradójico si se considera que en este mismo capítulo se ha señalado la ausencia de evidencia estadística, especialmente en lo que toca a 
rendimiento, que sugiriera la conveniencia de fomentar la forma de propiedad individual sobre la colectiva ${ }^{77}$; inclusive puede afirmarse que al menos para 1990 - a diez años de la reforma agraria-, el sector reformado mostró ser más productivo que el sector agrícola privado del país en el cultivo de granos básicos y cultivos de exportación, como la caña y el algodón, pese a ser uno de los sectores agrícolas con peor asistencia crediticia del país.

La actuación del gobiemo a través del Instituto Salvadoreño de Transformación Agraria (ISTA), FINATA y MAG, entre otros, se vuelve más cuestionable si se considera que existen datos que permiten concluir cuál de las dos formas de tenencia de la tierra - individual o colectiva - es la que produce mayores niveles de rendimiento. Obviamente la pequeña producción agropecuaria es la más ineficiente de todo el sector agropecuario.

De acuerdo con información del MAG, contenida en la IX Evaluación del Proceso de Reforma Agraria, para la cosecha correspondiente a los años 1988/ 89 el cultivo de granos básicos, como el maíz y el arroz, representó uno de los mayores rendimientos de las propiedades cultivadas bajo formas individuales de propiedad, mientras que el frijol y el maicillo se cultivaron más eficientemente en las propiedades colectivas ${ }^{78}$.

Por otra parte, para el ciclo agrícola 1989/90, el MAG también logró establecer que la adopción del Modelo Experimental de Adjudicación Individual (MEAI) no produjo formas de explotación más $\longrightarrow$ al menos igualmente- eficientes que las existentes en ese momento. Considérese que las parcelas bajo el MEAI, dedicadas al cultivo de granos básicos, obtuvieron un rendimiento de 30.8 quintales por hectárea, mientras que las formas de explotación individual pero adscritas a las cooperativas obtuvieron 51.4 quintales por hectárea, y las formas de explotación colectivas arrojaron un rendimiento de 59.74 quintales por hectárea.

El gobiemo podría calificar de pobre el desempeño de las propiedades afectadas por el proceso de reforma agraria, apoyándose en hechos como la disminución del área en el que se desarrolla la reforma agraria, el bajo aporte que el sector reformado da a la producción agropecuaria nacional, y la reducción de la participación de las tierras explotadas bajo formas de producción agrícola; pero esta calificación no puede ser extraída de su contexto específico. El hecho de que el sector reformado haya sido capaz de obtener niveles de rendimiento superiores a los obtenidos a nivel nacional durante la década pasada, es el principal hecho que evidencia la potencialidad de las formas de organización implementadas en el interior de las cooperativas de la primera etapa de la reforma agraria.

La política de los gobiemos del partido Alianza Republicana Nacionalista (ARENA) para el sector reformado parte de un supuesto fracaso del cooperativismo para luego promover la adopción de formas de propiedad privada individual, sin considerar antes cuáles son las lecciones que podrían tomarse de la 
experiencia de la reforma agraria. Se propone erradicar el cooperativismo sin aceptar que éste demostró gran capacidad de maniobra en un ambiente crediticio y político muy desfavorable.

Sin embargo, en el actual escenario, el cooperativismo parece estar cediendo ante el ofrecimiento de formas de propiedad privada hecho a sus integrantes. Por lo anterior, no sería remoto esperar una virtual desaparición de las cooperativas de la primera etapa de la reforma agraria, pese a que -en su momento- sus formas de organización mostraron que podrían ser una opción viable para combatir la pobreza rural. De hecho, esta posibilidad se evidenció con gran claridad durante el inicio de la presente década ${ }^{79}$.

\section{Consideraciones finales}

1. La reforma agraria alteró el uso de los suelos en el área afectada, lo cual provocó la disminución de los cultivos de alimentos y de algodón en las áreas correspondientes.

2. Los cultivos de maíz, maicillo, algodón y caña de azúcar, que aún se desarrollaban en el sector reformado a principios de la década de 1990, ofrecían mayores rendimientos que el nivel nacional.

3. El empleo en las cooperativas del sector reformado ha sufrido una drástica reducción como resultado de la disminución generalizada de la actividad agropecuaria.

4. La marginación del sector agropecuario y, en especial, del sector reformado de las fuentes crediticias, explican enormemente la reducción de la producción agropecuaria en general.

5. La política gubemamental hacia el sector reformado revela un marcado sesgo en contra de la propiedad cooperativa, basándose en argumentos ideologizados que interpretan la crisis de las cooperativas al margen de la crisis general del sector agropecuario.

6. A mediano plazo, la política de parcelación de las cooperativas podría resultar exitosa si se utiliza en el contexto de la crisis general del sector agropecuario.

7. El futuro del cooperativismo dependerá de su habilidad para capitalizar sus "ventajas comparativas" en lo tocante a la productividad de los cultivos; aunque mayormente dependerá del desarrollo de políticas de fomento del cooperativismo, en especial de capacitación y apoyo crediticio.

8. Cualquier estrategia de reactivación del agro debería tomar en cuenta el potencial de las cooperativas para optimizar el uso de los recursos, y su enorme potencialidad para superar la pobreza rural característica de las familias que cultivan pequeñas parcelas. 


\section{Referencias bibliográficas}

Alvarado, N. y Cruz, J. Conciencia y cambio social en la Hacienda Tres Ceibas (El Salvador): 1955-1976. Tesis de Licenciatura en Sociología. Universidad de Costa Rica, 1978.

Arévalo, A. et al. Efectos de la reforma agraria salvadoreña sobre las formas de producción y las condiciones de vida del campesino cooperativizado de FESACORA. Tesis de Licenciatura en Economía. San Salvador, Universidad Centroamericana "José Simeón Cañas", 1987.

Castilo, J. Intentos de reforma agraria en El Salvador. Tesis de Licenciatura en Sociología. San Salvador, Universidad de El Salvador, 1983.

Centro de Investigaciones Tecnológicas y Científicas (CENITEC). El futuro de las asociaciones cooperativas del sector reformado. San Salvador, 1990.

Centro Universitario de Documentación e Información (CUDI). "Persiste el problema agrario". En El Salvador Proceso, 11, 473, 1991, pp. 10-12.

Centro Universitario de Documentación e Información (CUDI). "La ineficiencia del sector reformado: un tabú que se desmorona". En El Salvador Proceso, 12, 478, 1991a, pp. 8-11.

Centro Universitario de Documentación e Información (CUDI). "Tendencias en la propiedad del sector reformado". En El Salvador Proceso, 12, 497, 1991b, pp. 4-8.

Centro Universitario de Documentación e Información (CUDI). "Crédito al sector agropecuario". En El Salvador Proceso, 16, 690, 1995, pp. 6-8.

Colindres, E. Fundamentos económicos de la burguesía salvadoreña. San Salvador: UCA Editores, 1977.

Consejo Asesor de la Reforma Agraria (CARA). Fundamentos y perspectivas del proceso de reforma agraria en El Salvador. San Salvador, 1988.

Diskin, M. Agrarian Reform in El Salvador. An Evaluation. Institute for Food and Development Policy, San Francisco California, 1985.

Flores, A. Surgimiento y desarrollo de las organizaciones populares en El Salvador, 1970-1980. Tesis de Maestría en Cicncias Sociales. México, FLACSO, 1983.

Loehr, W. y Núñez, R. El Salvador: An assesment of the impact of recent policy changes on agriculture, USAID, s.l., 1991.

Marroquín, V. Manual de economía agrícola salvadoreña. San Salvador, 1992.

Mejía, A. y Peña, V. Factores que inciden en la viabilidad de las cooperativas agropecuarias de la fase I de la reforma agraria en El Salvador, 1980-1988. Tesis de Licenciatura en Sociología. San Salvador, Universidad Centroamcricana "José Simeón Cañas", 1989.

Menjívar, R. Acumulación originaria y desarrollo de capitalismo en El Salvador. San José, EDUCA, 1980.

Molina, A. Consideraciones sobre la reforma agraria en El Salvador. Tesis de Ingenicría Agronómica. San Salvador, Universidad de El Salvador, 1963.

Montes, S. El agro salvadoreño (1973-1980). San Salvador, Universidad Centroamericana "José Simeón Cañas", 1978.

Montes, S. “¿Cuál es el modo de producción dominante en El Salvador?”. Boletín de Ciencias Económicas y Sociales, enero-f cbrero, 1983.

Montes, S. "El Salvador: la tierra, epicentro de la crisis". Boletín de Ciencias Económicas y Sociales, julio-agosto, 1986. 
Montes, S. "Levantamientos campesinos en El Salvador". Boletín de Ciencias Económicas y Sociales, enero-febrcro, 1988.

Montoya, A. "El agro salvadoreño antes y después de la reforma agraria". Cuadernos de investigación, No. 9, 1991.

Morales, 0 . "La estructura productiva antes y después de la reforma agraria". Presencia, 4, 1989.

Oficina Sectorial de Planificación Agropecuaria. IX Evaluación del proceso de reforma agraria, San Salvador, Ministerio de Agricultura y Ganadería, 1990.

Oficina Sectorial de Planificación Agropecuaria. X Evaluación del proceso de reforma agraria, San Salvador, Ministerio de Agricultura y Ganadería, 1991.

Oficina Sectorial de Planificación Agropecuaria. Evaluación del proceso de reforma agraria (marzo de 1980 a abril de 1982), San Salvador, Ministerio de Agricultura y Ganadería, 1982.

Rebollo, R. et al. Análisis y replanteamiento del marco institucional para el desarrollo y consolidación de la reforma agraria. San Salvador, CONDECORA, 1986.

Rubén, R. "El problema agrario en El Salvador: notas sobre una economía agraria polarizada". Cuadernos de investigación, No. 7, 1991.

Santillana, J. La administración en el sector cooperativo salvadoreño reformado (19791986). Departamento de Ahuachapán. Tesis de Licenciatura en Administración de Empresas. San Salvador, Universidad Centroamericana “José Simeón Cañas”, 1987.

Universidad de El Salvador. "Ponencias y resoluciones del Primer Congreso Nacional de Reforma Agraria, celebrado del 5 al 10 de enero de 1970". La Universidad, No. 1, 1970.

\section{Notas}

1. Director del Centro de Información, Documentación y Apoyo a la Investigación (CIDAI) de la Universidad Centroamcricana "José Simeón Cañas".

2. Analista económico del CIDAI.

3. Cfr. S. Montes, "El Salvador: la tierra, epicentro de la crisis". Boletín de Ciencias Económicas y Sociales, IX, Vol. 4, pp. 240-256; S. Montes, "Levantamientos campesinos en El Salvador", Realidad Económico-Social, I, Vol. 1, pp. 78-100.

4. Corresponde al sentido que Segundo Montes da a estos conceptos y que nosotros asumimos en esta investigación, Cfr. S. Montes, El agro salvadoreño (1973-1980), Cap. 2 ("Marco teórico: definiciones e hipótesis"). En este sentido, en esta parte del trabajo será más explícita la utilización de un marco categorial de procedencia marxista. Por otra parte, no entraremos a la discusión del carácter capitalista de la sociedad salvadoreña. Para este tema, $C$ fr. S. Montes, “¿Cuál es el modo de producción dominante en El Salvador?”, Boletín de Ciencias Económicas y Sociales, enero-febrero, 1983, pp. 30-37; R. Menjívar, Acumulación originaria y desarrollo del capitalismo en El Salvador, San José, Costa Rica, EDUCA, 1980; E. Colindres, Fundamentos económicos de la burguesía salvadoreña, San Salvador: UCA Editores, 1977.

5. Ministerio de Agricultura y Ganadería (MAG), Sector público agropecuario en El Salvador, No. 28 , s.f.

6. C.R. Cabarrús, "El Salvador. De movimiento campesino a revolución popular". En P. González Casanova (Coordinador), Historia política de los campesinos latinoamericanos, México: Siglo XXI-Instituto de Investigaciones Sociales de la UNAM, 1985 , p. 85. 
7. C.R. Cabarrús, ibid., pp. 85-91.

8. C.R. Cabarrús, ibid,. p. 87.

9. S. Montes, ibíd., p. 100. La fuente en que se apoya Segundo Montes es en la Revista mensual del Banco Central de Reserva (BCR), febrero, 1980.

10. S. Montes, ibid., p. 100.

11. CONAPLAN-MAG, citado por S. Montes, ibíd., p. 90.

12. S. Montes, ibid., p. 101.

13. MAG-OSPA. Datos sobre la producción obtenidos del Banco Central de Reserva de El Salvador y recabados por S. Montes, ibíd., p. 98. Las cifras están calculadas en miles de colones salvadoreños.

14. Revista del Banco Central de Reserva de El Salvador, septiembre de 1979.

15. Revista Central del Banco Central de Reserva, septiembre de 1979.

16. S. Montes, ibid., p. 104.

17. Cfr. Índice de volumen de la producción agropecuaria (1973-1977), Revista del Banco Central de Reserva, febrero, 1980.

18. S. Montes, ibid., p. 107.

19. CIID-OEA, Diagnóstico del sector agropecuario IPCT (Instrumentos y mecanismos de políticas científicas y tecnológicas).

20. Datos del Banco Central de Reserva de El Salvador, Departamento de Investigaciones económicas, febrero, 1980.

21. S. Montes, ibid., p. 122.

22. Ministerio de Planificación (MIPLAN), "Distribución del ingreso monetario mensual (1975-1979)", Encuestas de Unidad de Investigaciones Muestrales, 1979. Las cifras están calculadas en miles de colones salvadoreños.

23. S. Montes, ibíd., p. 123.

24. Decimos en general porque no sólo se trata de una depauperación provocada por los bajos niveles de ingreso o la escasez de productos básicos de alimentación, sino por el deterioro de la vivienda, la salud, la educación, etc., que, en su conjunto, hicieron de la mayor parte de la población rural de El Salvador una población extremadamente empobrecida.

25. S. Montes, ibid., p. 125.

26. S. Montes, ibid., p. 125.

27. S. Montes, ibid., p. 126.

28. Primer y Tercer Censo Nacional Agropecuario, 1950 y 1971. S. Montes, ibíd., pp. 125-128.

29. C.R. Cabarrús, ibid., p. 92.

30. Dirección General de Estadística y Censos (DIGESTYC), Empleo y desempleo en El Salvador, San Salvador, DIGESTYC, 1973. p. 19.

31. S. Montes, ibid., p. 142.

32. Para el análisis del proceso de transformación agraria ver Cfr. I. Ellacuría, "El primer proyecto de transformación agraria", Veinte años.., Vol. I, pp. 559-566; I. Ellacuría, "Un marco teórico valorativo de la reforma agraria", ibíd., pp. 567-586; I. Ellacuría, "La transformación de la ley del Instituto de Transformación Agraria", ibid., pp. 629-648.

33. Art. 1. "El proyecto tiene una extensión superficial de cincuenta y ocho mil setecientos cuarenta y cuatro hectáreas ( $58744 \mathrm{Ha}$ ) ubicado en las jurisdicciones de los Municipios de Jiquilisco, Ozatlán, Usulután, Santa María, Ereguayquín, Concepción 
Batres y Jucuarán, todos del departamento de Usulután y los municipios de El Tránsito, San Miguel y Chirilagua del departamento de San Miguel", Estudios Centroamericanos (ECA), septiembre-octubrc, 1976, pp. 606-610.

34. Cfr. Estudios Centroamericanos (ECA), septiembre-octubre, 1976, pp. 591-606.

35. Estudios Centroamericanos (ECA), ibid.

36. Este es el título de un editorial de la Revista Estudios Centroamericanos (ECA), de la Universidad Centroamericana "José Simeón Cañas", escrito a propósito de la debilidad del gobierno de Molina ante la derecha salvadoreña. El editorial le costó a la universidad el subsidio gubernamental del que hasta el momento gozaba. Cfr. "A sus órdenes, mi capital", Estudios Centroamericanos (ECA), XXXI, 337, pp. 637-643.

37. Para el análisis de los cambios introducidos por el decreto 123, Cfr. el editorial de la revista $E C A$ "A sus órdenes, mi capital”, ya citado.

38. Caracterización del Estado liberal y la función desempeñada por la Iglesia en sus relaciones con el mismo, Cfr. R. Cardenal, El poder eclesiástico en El Salvador (18711931), San Salvador: UCA Editores, 1980, pp. 19-75; Cfr. L. North, Bitter grounds: roots of revolts in El Salvador, Ontario, Between the lines, 1981, Cap. 2 (“'Liberal revolution': establishment of a cofee republic").

39. R. Cardenal, ibid., p. 7.

40. R. Cardenal, ibid., p. 219.

41. Extractos importantes del documento de Mons. Belloso y Sánchez han sido recopilados por Jorge Arias Gómez, en su libro Farabundo Martí, San José, Costa Rica, EDUCA, 1972, pp. 39-58.

42. Texto citado por S. Arias Gómez, ibid., p. 45.

43. Ibid., p. 45-46.

44. Esta tradición fue cancelada por Mons. Oscar A. Romero, quien se negó a oficiar el consabido Te Deum al gobierno entrante del general Carlos Humberto Romero, en 1977, en protesta por el asesinato del P. Rutilio Grande, el 12 de marzo de 1977.

45. El caso más evidente sucedió en el momento de la elección del nuevo Arzobispo de San Salvador, tras el retiro de Mons. Luis Chávez y González. Entre Mons. Arturo Rivera Damas -un obispo de orientación demasiado progresista ante los ojos de los grupos de poder- y Mons. Oscar Arnulfo Romero - caracterizado por sus posiciones conservadoras-, la oligarquía presionó incluso a nivel del Vaticano para la elección del segundo de los candidatos. Como lo atestigua el mismo Mons. Romero en su Diario, los ofrecimientos económicos se hicieron sentir casi inmediatamente después de su elección, así como cuando el Arzobispo comenzó a dar muestras del viraje religioso y político que le llevaría a enfrentarse con la oligarquía y el gobierno del general Romero

46. Para el análisis de esta experiencia de trabajo eclesial en el campo salvadoreño, $C f r$. Alvarado López, et. al., Conciencia y cambio social en la Hacienda Tres Ceibas (El Salvador), Licenciatura Centroamericana en Sociología, San José, Costa Rica, 1978.

47. Paternalismo, porque se ve a los campesinos como sujetos pasivos de la política eclesial, que reciben de los agentes clericales las orientaciones organizativas que ellos consideran necesarias. Asistencialismo, porque se trata de llevar a los pobladores del campo una ayuda pastoral que sirva de paliativo a sus ingentes necesidades. Esta ayuda se canalizaba a través de una instancia eclesial llamada "Cáritas de El Salvador", que a su vez canalizaba - por si hubiese dudas acerca de su carácter asistencial- alimentos, ropa, etc., de Alianza para el progreso. 
48. Cfr. I. Ellacuría, "La Iglesia y las organizaciones populares", Veinte años..., Vol. II, pp. 659-678.

49. Los miembros de la jerarquía eclesial que se confrontaron de manera más directa con la nueva evangelización y directamente con la orientación eclesial de Mons. Romero fueron Pedro Amoldo Aparicio y Quintanilla, Obispo de San Vicente y Secretario General de la CEDES; Benjamín Barrera y Reyes, Obispo de Santa Ana; José Eduardo Alvarez, Obispo de San Miguel y Vicario Castrense; Marco René Revelo, Obispo Auxiliar de San Salvador; y Freddy Delgado, Secretario General de la CEDES.

50. La oposición de la Conferencia Episcopal de El Salvador - a excepción de Mons. Arturo Rivera Damas- a la opción del Arzobispado de San Salvador y del clero cercano a esta opción, fue in crescendo desde el desacuerdo con el trabajo pastoral de Rutilio Grande hasta llegar a la ruptura en los últimos meses del ejercicio de Mons. Oscar Romero. Por su parte, la reacción de la élite del poder comenzó con el estallido de 6 bombas en la Universidad Centroamericana "José Simeón Cañas" y una bomba en la imprenta del Arzobispado, en 1976, a lo que siguió, un año después, la expulsión de 6 religiosos extranjeros (2 seminaristas S.J., 1 ex sacerdote S.J., 2 sacerdotes diocesanos y 1 mariknoll). Este ciclo de violencia contra la Iglesia continúa con los asesinatos del P. Rutilio Grande y dos campesinos que lo acompañaban, así como del P. Alfonso Navarro Oviedo, en 1977; Ernesto Barrera Moto, en 1978, y los padres Octavio Ortiz, Rafael Palacios y Alirio Napoleón Macías, en 1979. Este ciclo de violencia contra la Iglesia alcanzó su punto culminante con el asesinato de Mons. Óscar Romero, en marzo de 1980. Evidentemente, aquí sólo hemos reseñado algunos casos de violencia que afectaron directamente al cuerpo clerical, pero la violencia se hizo sentir más y con mayor impunidad - durante el período que consideramos y después de la muerte de Mons. Romero- sobre religiosas y religiosos, delegados de la palabra y creyentes. C $f r$. Comisión de Derechos Humanos de EI Salvador, La Iglesia en El Salvador, San Salvador: UCA Editores, 1982; Brockman, J. R., La palabra queda..., pp. 9 y ss.

51. Pedro Amoldo Aparicio y Quintanilla, Benjamín Barrera y Reyes, José Eduardo Alvarez, Marco rené Revelo, Freddy Delgado, "Declaración de cuatro Obispos de la Conferencia Episcopal”, 28 de agosto de 1978. En Romero, O. A., et. al., Iglesia de los pobres y organizaciones populares, San Salvador: UCA Editores, 1979, pp. 63-65.

52. Comunicado del Consejo Coordinador de FARO, publicado en La Prensa Gráfica el 31 de mayo de 1977. Reproducido en el libro de la Comisión de Derechos Humanos de El Salvador, La Iglesia en El Salvador, San Salvador: UCA Editores, 1982, pp. 38-38. Las mayúsculas son del original y se refieren a Monseñor Óscar A. Romero.

53. Cachete: favor.

54. UGB: Unión Guerrera Blanca, escuadrón de la muerte.

55. Volante citado en el libro de la Comisión de Derechos Humanos de El Salvador, ibíd., pp. 40-42. Las mayúsculas son del original ("Hacer el cachete": expresión popular salvadoreña que significa hacer el favor; UGB = Unión Guerrera Blanca, grupo paramilitar —escuadrón de la muerte- que efectuó gran número de acciones terroristas —ajusticiamientos, desapariciones, amenazas, etc. - contra religiosos y religiosas, maestros, estudiantes, campesinos y obreros vinculados al movimiento popular). 
56. C.R. Cabarrús, ibíd., p. 145. El relato de Cabarrús es tanto más interesante en cuanto que él no sólo investigó como antropólogo la experiencia de Aguilares, sino que se invplucró como sacerdote jesuita en la tarea evangelizadora encabezada por el P. Grande.

57. C.R. Cabarrús, ibid., p. 146.

58. C.R. Cabarrús, ibid., p. 146.

59. C.R. Cabarrús, ibid., p. 148.

60. Ficha de trabajo de C. R. Cabarrús, ibid., p. 170.

61. Ficha de trabajo de C. R. Cabarrús, ibid., p. 149.

62. Ibid., p. 150.

63. Ibid.

64. Ibid.

65. T.S. Montgomery, "Doce años en El Salvador...". p. 643.

66. En este punto es pertinente hacer notar que - de acuerdo con los autores- es un error pensar que la organización campesina gestada en esa época fue una creación puramente eclesial, es decir, algo introducido desde fuera incluso con una planificación previa. La Iglesia animó y respaldó la organización campesina, pero — según los autores - fueron los mismos campesinos quienes decidieron sus formas organizativas y la orientación reivindicativa y/o política de las mismas, y csto escapó al control de los grupos eclesiales que quedaron muchas veces a la zaga de la dinámica popular.

67. Simon y Stephens, 1981 , p. 173.

68. Simon y Stephens, 1981, p. 175.

69. Elaboración propia con base en la información de OSPA, 1991, y el MAG, 1990.

70. De acuerdo con datos del Banco Central de Reserva, entre 1980 y 1991 la participación del sector agropecuario en el Producto Interno Bruto (PIB) descendió del 27.82 al 16.5 por ciento, respectivamente.

71. Este punto de vista también puede encontrarse en CUDI, 1991, p. 9.

72. Montoya, 1991, pp. 99-101.

73. Núñez y Loehr, 1991, p. 73.

74. CUDI, 1995, p. 6.

75. CUDI, 1991, p. 12.

76. CUDI, 1991, pp. 10-11.

77. CUDI, 1991; CUDI, 1991a y CUDI, $1991 b$.

78. OSPA, 1989.

79. Cfr. CENITEC, 1990. 